MODELING, IDENTIFICATION AND CONTROL, 1995, VOL. 16, NO. 4, 193-212 doi:10.4173/mic.1995.4.2

\title{
Mathematical modeling of a rotary hearth coke calciner
}

\author{
H. C. MEISINGSET $\dagger$ and J. G. BALCHEN $\dagger$
}

Keywords: First principles modeling, distributed process, coke calcination, combustion, heat transfer.

\begin{abstract}
A mathematical model of a rotary hearth coke calciner is developed. The model is based on first principles including the most important dynamic phenomena. The model is a thermodynamic model involving heat and mass transfer and chemical reactions. Fundamental mass and energy balance equations for the coke phase, the gas phase and the lining are formulated. For the gas phase, a stationary model is used. The equations are solved numerically, and simulated temperature profiles are shown in this paper.
\end{abstract}

\section{Introduction}

Petroleum coke is a hard and brittle substance, high in fixed carbon and low in ash. It is one of the purest forms of carbon produced in large quantities. Petroleum coke is produced from various petroleum residual fractions. Temperatures of about $500^{\circ} \mathrm{C}$ convert these resids into green coke within a day (Marsh 1989). A complex series of endothermic pyrolysis reactions produce liquid crystal mesophase which is transformed to a carbon polymer of generally graphitic structure. The result is a coke with a more or less anisotropic structure and related property values.

Most of the petroleum coke produced is used as filler material in the production of anodes for the aluminium industry. Coke for the aluminium industry must be calcined before use to produce quality anode carbon. This calcined coke should be relatively hard, strong, dense, with low electrical resistivity and oxidation sensitivity, high purity and available in aggregate sizing from $26 \mathrm{~mm}$ particles to cover standard anode filler sizing requirements (Jones 1986).

Most industrial coke calcination is done using rotary kiln calciners (Perron et al. 1988). Some industrial calcination is done in a rotary hearth calciner. Several calciner models have been reported in the literature (Perron et al. 1992). However, these models all refer to the rotary kiln calciner and include only steady state models.

In this paper, a dynamic model of a rotary hearth calciner is presented. The final coke quality depends on the thermal treatment of the coke. In order to develop a model based control system, it is therefore important to describe the thermodynamics of the calciner. The model is based on first principles including physical and chemical knowledge.

The paper is organized as follows: In $\S 2$ a short process description is given. In $\S 3$ the chemical reactions are presented. In $\$ 4$ heat transfer mechanisms are discussed. In $\S \S 5$ and 6 fundamental mass- and energy balance equations are formulated for the coke

Received 8 May 1995.

$\dagger$ The Norwegian Institute of Technology, Department of Engineering Cybernetics, N-7034 Trondheim. Norway. email: hilde@itk.unit.no 


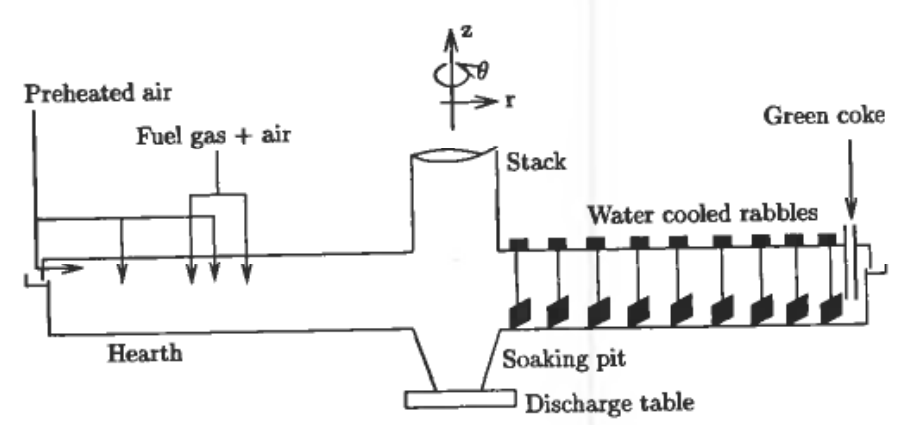

Figure 1. Schematic diagram of a rotary hearth calciner.

bed and the gas phase, respectively. In $\S 7$ the temperature of the lining is modeled. In $\S 8$ simulation results are presented. The conclusions are presented in $\S 9$.

\section{Process description}

The rotary hearth calciner consists of a horizontal rotating circular table or hearth (Fig. 1). The rotating hearth is inside a furnace chamber. Green coke is fed from a feed bin through a feedshute to the outermost edge of the hearth. On the ceiling a number of rabbles are mounted. The rabbles are guiding the coke in circular paths from the outermost edge to centre of the hearth. The rabbles are water cooled. In the centre of the hearth, the coke falls into a soaking pit before removal from the calciner. Air is supplied through a number of wickets on the ceiling and in the side wall. Several burners are located on the ceiling. During transportation, the coke is heated from the surrounding gas and the lining. Coke moisture is then removed and upon further heating, volatile matter is released and burned in the gas phase. Most of the energy is supplied through volatile combustion. In addition, energy can be supplied by the burners.

The exhaust gas flows through the stack under the influence of a fan controlling the gas pressure. The exhaust gas is further utilized in a steam generator.

During calcination, the overall composition and stuctural properties of the coke change. The green coke contains typically $8-10 \%$ moisture and $8-10 \%$ volatile matter. All of the moisture and most of the volatiles are assumed removed during normal operation. Calcined coke is a rather pure carbon except for the sulphur content. Also, metallic impurities of few tenths of one percent are present.

For modeling purposes, the calciner will be divided into three parts

- The coke bed

- The gas phase

- The lining (hearth, roof and walls above the bed)

Mass is exchanged between the coke bed and the gas phase. Heat is exchanged between the coke bed, the gas phase and the lining.

\section{Chemical reactions}

During calcination several phenomena take place

- Water evaporation from the coke bed

- Release of volatiles from the coke bed

- Combustion of the volatiles and fuel gas in the gas phase 
- Combustion of the coke bed

- Dust generation

It is assumed that the hydrocarbons are burned in the gas phase and not in the coke bed. Sulphur release will not be considered. Sulphur release is assumed to occur at higher temperatures than the maximum temperature of the coke during normal calciner operation, (Rhedey 1967).

\subsection{Evaporation of water}

The evaporation of water can be expressed by the reaction

$$
\mathrm{H}_{2} \mathrm{O}(l) \rightarrow \mathrm{H}_{2} \mathrm{O}(\mathrm{g})
$$

This is an endothermal process. According to Perron et al. (1992), the rate of evaporation may be modeled by an Arrhenius rate law. Let $g_{\mathrm{H}_{2} \mathrm{O}}\left(\left[\mathrm{kg} / \mathrm{m}^{3} \mathrm{~s}\right]\right)$ denote the rate of evaporation of water written

where

$$
g_{\mathrm{H}_{2} \mathrm{O}}=k_{\mathrm{H}_{2} \mathrm{O} .0} \cdot e^{-E_{\mathrm{H}_{2} \mathrm{O} / R T_{c}}} \cdot x_{\mathrm{H}_{2} \mathrm{O}} \cdot \rho_{c}
$$

\footnotetext{
$x_{\mathrm{H}_{2} \mathrm{O}}$ mass fraction of water in the coke $[\mathrm{kg} / \mathrm{kg}]$

$k_{\mathrm{H}_{2} \mathrm{O}, 0}$ pre-exponential factor $\left[\mathrm{s}^{-1}\right]$

$E_{\mathrm{H}_{2} \mathrm{O}}$ activation energy [J/mole K]

$\rho_{c}$ coke bed density $\left[\mathrm{kg} / \mathrm{m}^{3}\right]$

$T_{c} \quad$ coke bed temperature [K]
}

The values for $k_{\mathrm{H}_{2} \mathrm{O}}$ and $E_{\mathrm{H}_{2} \mathrm{O}}$ are taken from Perron et al. (1992).

\subsection{Release of volatile matter}

The devolatilization starts with the release of condensable hydrocarbons. This is followed by the release of noncondensable hydrocarbons, mainly hydrogen and methane (Charette et al. 1992). The devolatilization is a complex process. The details will not be considered here. The devolatization will simply be expressed by a stoichiometric equation of the form

$$
X(s) \Rightarrow Y(s)+Z(\mathrm{~g})
$$

where $X$ represents the green coke, $Y$ the calcined coke and $Z$ the gaseous reaction products. In modeling the release of volatile matter, the following are assumed

- The volatiles are lumped into three components: hydrogen $\left(\mathrm{H}_{2}\right)$, methane $\left(\mathrm{CH}_{4}\right)$ and $\operatorname{tar}\left(\mathrm{C}_{18} \mathrm{H}_{12}\right)$

- The releases are described by independent reactions

According to Dernedde et al. (1986), the rate of the release of component $i$ may be modeled by an Arrhenius-like rate equation

$$
\frac{d \eta_{i}}{d t}=-k_{0, i} e^{-E_{i} / R T_{c}}\left(\eta_{i}\right)^{n_{i}}
$$

where

$$
\begin{aligned}
k_{i, 0} & \text { pre-exponential factor }\left[\mathrm{s}^{-1}\right] \\
E_{i} & \text { activation energy } \\
i & \text { component } i \in\left[\mathrm{H}_{2}, \mathrm{CH}_{4}, \mathrm{C}_{18} \mathrm{H}_{12}\right]
\end{aligned}
$$


$\eta_{i} \quad$ fraction of component $i$ not converted $\left.\eta_{i}\right|_{t=0}=1$

$n_{i}$ reaction order

Let $x_{i, 0}([\mathrm{~kg} / \mathrm{kg}])$ denote the initial mass fraction of component $i$ in the coke. Let $\rho_{c, 0}$ denote the initial coke density. The volatile emission rate, $g_{i}\left(\left[\mathrm{~kg} / \mathrm{m}^{3} \mathrm{~s}\right]\right)$, can then be found

$$
g_{i}=-x_{i, 0} \cdot \rho_{c, 0} \cdot \frac{d \eta_{i}}{d t}
$$

The parameters used in the rate expressions are taken from Dernedde et al. (1986).

\subsection{Dust generation}

Production of carbon dust at the surface of the bed is influenced by several factors. $\mathrm{Li}$ and Friday (1974) have developed a rate expression for the generation of dust in a rotary kiln calciner. The variables influencing the dust generation in a rotary kiln are

(1) kiln rotational speed

(2) gas density, viscosity and velocity

(3) coke density

(4) coke moisture and volatile release

Compared to the dust generation in a rotary kiln calciner, the dust generation in a rotary hearth calciner is much smaller (Brandt 1986). This is mainly due to the reduced mechanical abrasion in the rotary hearth compared to the rotary kiln.

A dust generation rate law will be proposed based on the above discussion. Let $g_{d}$ $\left(\left[\mathrm{kg} / \mathrm{m}^{3} \mathrm{~s}\right]\right)$ denote the dust generation rate. The generation is written

$$
g_{d}=k_{d} \cdot \mu_{g}^{n_{1}} \cdot v_{g}^{n_{2}} \cdot \rho_{g}^{n_{3}} \cdot \rho_{c}^{n_{4}} \cdot x_{H_{2}}^{n_{5}} O \cdot \omega^{n_{6}}
$$

where

$$
\begin{array}{ll}
\mu_{g} & \text { gas viscosity }[\mathrm{kg} / \mathrm{ms}] \\
\rho_{g} & \text { gas density }\left[\mathrm{kg} / \mathrm{m}^{3}\right] \\
\rho_{c} & \text { coke bed density }\left[\mathrm{kg} / \mathrm{m}^{3}\right] \\
v_{g} & \text { gas velocity }[\mathrm{m} / \mathrm{s}] \\
k_{d} & \text { parameter } \\
\omega & \text { rotational speed }
\end{array}
$$

The gas viscosity is assumed to be proportional to the square root of the gas temperature. Assuming the ideal gas law and approximately constant pressure, the gas density is modeled inversely proportional to the gas temperature

$$
g_{d}=k_{d} \cdot T_{g}^{m_{1}} \cdot v_{g}^{m_{2}} \cdot \rho_{c}^{m_{3}} \cdot x_{H_{2} O}^{m_{4}} \cdot \omega^{m_{5}}
$$

The parameters $k_{d}$ and $m_{i}$ should be estimated according to dust generation data.

\subsection{Combustion of the coke bed}

During normal calciner operation, oxygen excess will be assumed and the temperature regime is below $2000^{\circ} \mathrm{C}$. Therefore, only the overall reaction will be considered

$$
\mathrm{C}+\mathrm{O}_{2} \rightarrow \mathrm{CO}_{2}
$$

It will be assumed that the reaction takes place at the surface of the coke bed and that 
the reaction rate is proportional to the diffusion of oxygen from the gas bulk to the coke bed surface (Kanury 1977).

Let $y_{\mathrm{O}_{2}}$ denote the oxygen concentration in the gas phase. The diffusion of oxygen can be written by Fick's first law:

$$
J=D_{O_{2}} \nabla y_{O_{2}}
$$

where $D_{O_{2}}$ is the diffusivity constant. At the coke bed surface, the oxygen concentration will be assumed equal to zero due to the assumed fast reaction kinetics. The burning rate, $g_{c}$, will then be assumed proportional to the oxygen concentration in the gas phase:

$$
g_{c}=k_{c} \cdot y_{O_{2}}
$$

where $y_{\mathrm{O}_{2}}$ is the oxygen concentration in the gas phase and $k_{c}$ is the proportionality constant. The combustion of dust is assumed to follow the same rate expression.

\subsection{Combustion of volatiles}

The hydrocarbons are burned in the gas phase. It is assumed that the combustion is complete. The combustion equations can then be written

$$
\begin{aligned}
2 \mathrm{H}_{2}+\mathrm{O}_{2} & \rightarrow 2 \mathrm{H}_{2} \mathrm{O}-\Delta \mathrm{H}_{\mathrm{H}_{2}} \\
\mathrm{CH}_{4}+2 \mathrm{O}_{2} & \rightarrow \mathrm{CO}_{2}+2 \mathrm{H}_{2} \mathrm{O}-\Delta \mathrm{H}_{\mathrm{CH}_{4}} \\
\mathrm{C}_{18} \mathrm{H}_{12}+21 \mathrm{O}_{2} & \rightarrow 18 \mathrm{CO}_{2}+6 \mathrm{H}_{2} \mathrm{O}-\Delta \mathrm{H}_{\text {tar }}
\end{aligned}
$$

with $\Delta H_{h_{2}}=-120000 \mathrm{~kJ} / \mathrm{kg}, \Delta H_{C_{4}}=-50000 \mathrm{~kJ} / \mathrm{kg}$ and $\Delta H_{\text {tar }}=-39000 \mathrm{~kJ} / \mathrm{kg}$, (Perron et al. 1992).

The following rate expression will used for the combustion (Perron et al. 1988):

$$
g_{i}=k_{0, i} \cdot e^{-E_{i} / R T} \cdot \rho_{g}^{2} \cdot y_{i} \cdot y_{O_{2}}
$$

where

$$
\begin{aligned}
g_{i} & \text { rate of combustion }\left[\mathrm{kg} / \mathrm{m}^{3} \mathrm{~s}\right] \\
k_{0, i} & \text { pre-exponential factor } \\
y_{i} & \text { mass fraction of component } i \text { in the gas phase } \\
\rho_{g} & \text { gas density }\left[\mathrm{kg} / \mathrm{m}^{3}\right]
\end{aligned}
$$

The constants used in the rate expressions are taken from Perron et al. (1992).

\subsection{Combustion of fuel gas}

The fuel gas is assumed to be a mixture of methane, ethane, propane and butane. The combustion equation, assuming complete combustion, can be written

where

$$
a \mathrm{CH}_{4}+b \mathrm{C}_{2} \mathrm{H}_{6}+c \mathrm{C}_{4} \mathrm{H}_{10}+d \mathrm{O}_{2} \rightarrow e \mathrm{CO}_{2}+f \mathrm{H}_{2} \mathrm{O}-\Delta \mathrm{H}_{f}
$$

$$
\begin{aligned}
& d=2 \cdot a+3 \cdot 5 \cdot b+5 \cdot c+6 \cdot 5 \cdot d \\
& e=a+2 \cdot b+3 \cdot c+4 \cdot d \\
& f=2 \cdot a+3 \cdot b+4 \cdot c+5 \cdot d
\end{aligned}
$$




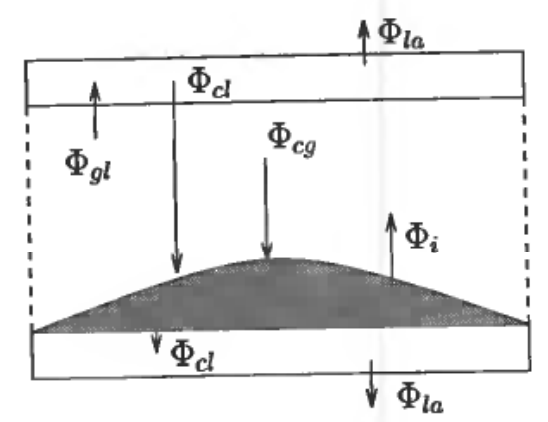

$\Phi_{c g}$ radiant and convective heat flux between the gas and the coke bed

$\Phi_{g l}$ radiant and convective heat flux between the gas and the lining

$\Phi_{c l}$ radiant and conductive heat flux between the coke bed and the lining

$\Phi_{l a}$ radiant and convective heat flux between the lining and ambient air

$\Phi_{i}$ heat flux due to evolution of component $i$ from the coke bed to the gas

Figure 2. Heat transfer between the coke bed, the gas phase and the lining.

The following coefficients are chosen: $a=0.962, b=0.014, c=0, d=0$ (Perron et al. 1992).

The fuel gas is supplied together with sufficient air. The reaction rate will be assumed infinitely high due to the assumption of good mixing between the air and fuel gas.

\section{Heat transfer in the calciner}

There are in general three modes of transfer which can be defined

(1) Conduction

(2) Convection

(3) Radiation

The heat transfer in the calciner is complicated and will involve all three modes of heat transfer. The heat flux pattern between the gas phase, the lining and the coke bed can be described by the following notation (Fig. 2). The figure illustrates a typical cross section of the coke bed in the rotational direction. In addition, heat conduction in the coke bed and in the lining, and heat transfer to the water cooled rabbles are considered. For the soaking pit, a similar illustration can be made.

The relative importance of the modes of heat transfer very much depends on the temperature. In high temperature processes, radiative heat transfer will dominate.

\subsection{Radiative heat transfer}

For the radiative heat transfer the following assumptions will be made

- Total radiative properties will be considered

- The coke bed and the lining are grey and opaque

$$
\begin{aligned}
& \boldsymbol{\epsilon}=\alpha \\
& \tau=0 \Rightarrow \rho=1-\alpha
\end{aligned}
$$

- The gas is grey, transmitting and non-reflecting

$$
\epsilon_{g}=\alpha_{g}
$$




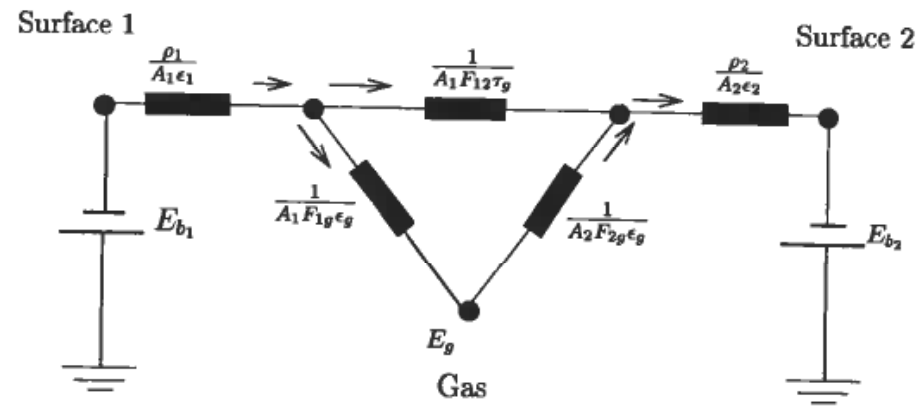

Figure 3. Thermal circuit for two finite plates with intermediate gas. From Kreith and Black (1980).

where $\epsilon$ denotes the emissivity, $\alpha$ denotes the absorptivity, $\rho$ denotes the reflectivity and $\tau$ denotes the transmissivity. The gas mixture emissivity can be found from emissivity diagrams for $\mathrm{H}_{2} \mathrm{O}$ and $\mathrm{CO}_{2}$ (Hottel and Sarofim 1967). In addition, the soot emissivity must be included. The soot emissivity depends on the soot concentration. The method of Modak (1978) can be used to find the soot radiative properties.

It will be assumed that the furnace length in the direction of gas flow is large compared to its height so that net radiative flux in the gas-flow direction can be ignored. Only flux in the direction normal to the flow will be considered.

Radiation between grey surfaces separated by a grey gas is considered in Kreith and Black (1980). The thermal circuit is shown in Fig. 3.

The radiation will be simplified by assuming that the surfaces are dark grey. The radiative exchange terms can be simplified because the contribution to the radiative exchange by beams that have undergone more than one reflection at the surfaces is small (Hottel and Sarofim 1967).

The radiation between the coke bed and the gas is expressed by

$$
\Phi_{r, g c}=F_{g c} \cdot \frac{\epsilon_{c}+1}{2} \cdot \sigma \cdot \epsilon_{g} \cdot\left(T_{g}^{4}-T_{c}^{4}\right)
$$

The radiation between the gas and the lining is expressed by

$$
\Phi_{r, g l}=F_{g l} \cdot \frac{\epsilon_{l}+1}{2} \cdot \sigma \cdot \epsilon_{g} \cdot\left(T_{g}^{4}-T_{l}^{4}\right)
$$

The radiation between the coke bed and the lining is expressed by

where

$$
\Phi_{r, c l}=F_{c l} \cdot \epsilon_{l} \cdot \epsilon_{c} \cdot\left(1-\epsilon_{g}\right) \cdot \sigma \cdot\left(T_{c}^{4}-T_{l}^{4}\right)
$$

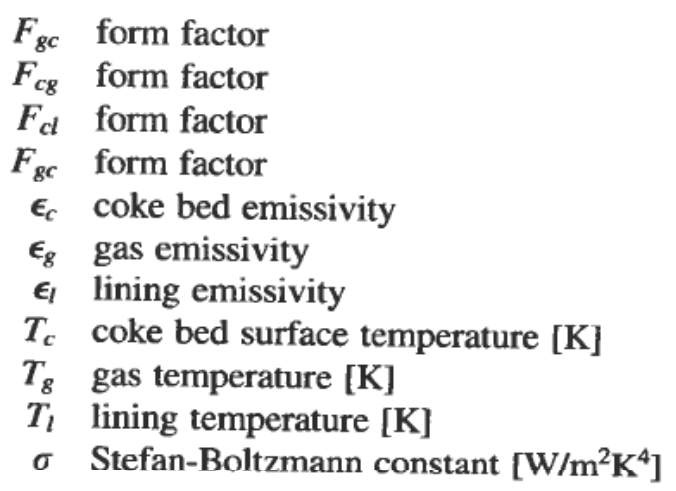




\subsection{Convective heat transfer}

Convective heat transfer between the gas and the lining, $\Phi_{c, g l}$, between the gas and the coke bed surface, $\Phi_{c, g c}$, and between the lining and the ambient, $\Phi_{c, l a}$, air are calculated from

$$
\begin{aligned}
& \Phi_{c, g c}=h_{g c} \cdot\left(T_{g}-T_{c}\right) \\
& \Phi_{c, g l}=h_{g l} \cdot\left(T_{g}-T_{l}\right) \\
& \Phi_{c, l a}=h_{l a} \cdot\left(T_{l}-T_{a}\right)
\end{aligned}
$$

where

$h_{g c}$ heat transfer coefficient gas to coke $\left[\mathrm{J} / \mathrm{m}^{2} \mathrm{~K}\right]$

$h_{g l}$ heat transfer coefficient gas to lining $\left[\mathrm{J} / \mathrm{m}^{2} \mathrm{~K}\right]$

$T_{c}$ coke surface temperature $[\mathrm{K}]$

$T_{g}$ gas temperature[K]

$T_{l} \quad$ lining temperature $[\mathrm{K}]$

$T_{a}$ ambient air temperature[K]

The convective heat transfer coefficients are calculated from correction for the Nusselt number $(\mathrm{Nu})$

$$
\mathrm{Nu}=\frac{h d}{k_{g}}
$$

where $h$ is the heat transfer coefficient, $d$ is the hydraulic diameter, $k_{g}$ is the gas thermal conductivity. Convective heat transfer between the gas and the lining and between the gas and coke bed are considered as forced convection. The forced convection is assumed to take place in the turbulent regime; $\operatorname{Re} \sim 60000$, (Storaker 1989). For turbulent gas in a circular tube:

$$
\mathrm{Nu}=0.02 \mathrm{Re}^{0.8} \operatorname{Pr}^{0.33}
$$

$\operatorname{Pr}$ is the Prandtl number. For all diatomic gases and for carbon dioxide, $\operatorname{Pr}=0.74$. For water vapour it is higher, but for ordinary furnace gases at atmospheric pressure $\operatorname{Pr}$ can usually be considered constant at the above figure (Gilchrist 1977).

For other geometries it is possible to use the equation for turbulent flow inside a circular pipe and use some equivalent diameter, $d_{e q}$, in the place of $d$ (Coulson and Richardson 1988). An equivalent diameter is defined as four times hydraulic radius:

$$
d_{e q}=4 \frac{\text { cross section of channel }}{\text { wetted perimeter }}
$$

For the external lining surfaces, a correlation for the Nusselt number for laminar free convection may be used. However, in this work a simplification is introduced by applying constant heat transfer coefficients.

\subsection{Conductive heat transfer} law)

Heat flux by by conduction is proportional to the temperature gradient (Fourier's

$$
\Phi_{c u n d}=-k \nabla T
$$


where

$\begin{array}{ll}k & \text { thermal conductivity }[\mathrm{W} / \mathrm{mK}] \\ T & \text { temperature }[\mathrm{K}]\end{array}$

Heat conduction is neglected in the gas phase. For the solid coke bed and the lining, heat conduction is included. The heat conduction is considered to be one dimensional.

The coke bed is considered as a thermally thick medium: This can be expressed by the dimensionless Biot-number (Bi) (Kreith and Black 1980):

$$
\mathrm{Bi}=\frac{h V}{k A}
$$

where

$h$ heat transfer coefficient from gas/lining to the coke bed $\left[\mathrm{J} / \mathrm{m}^{2} \mathrm{~K}\right]$

$V$ volume $\left[\mathrm{m}^{3}\right]$

$k$ thermal conductivity $[\mathrm{W} / \mathrm{mK}]$

$A$ area $\left[\mathrm{m}^{2}\right]$

In the case of $\mathrm{Bi}>1$, the solid is considered as a thermally thick medium.

For the coke bed, the effective heat transfer coefficient is due to both radiation and convection. Consider the case of heat transfer from the gas to the coke bed surface. Due to the high temperatures, the radiative heat transfer will dominate. The heat transfer coefficient can be approximated by

$$
h_{e f f} \approx \epsilon_{g} \frac{\epsilon_{c}+1}{2} \sigma \frac{T_{g}^{4}-T_{c}^{4}}{T_{g}-T_{c}}
$$

In the case of luminous flames, $\epsilon_{g}$ can be approximated to 1. Consider the case of a gas temperature $T_{g}=1000^{\circ} \mathrm{C}$, let $\epsilon_{c}=0.8$ and $k=1$ and suppose the coke bed height is $0.2 \mathrm{~m}$. $h_{e f f}$ and the $\mathrm{Bi}$ number for two different coke temperatures are approximately given by

$$
\begin{aligned}
& T_{c}=100^{\circ} \mathrm{C} \Rightarrow h_{\text {eff }}=73 \Rightarrow \mathrm{Bi}=15 \\
& T_{c}=500^{\circ} \mathrm{C} \Rightarrow h_{e f f}=115 \Rightarrow \mathrm{Bi}=23
\end{aligned}
$$

Due to the high $\mathrm{Bi}$ numbers computed, the coke bed will be modeled with heat conduction in the axial direction.

The same argument can be used for the lining.

Coke bed effective heat conductivity. The heat transfer in the coke bed is the result of conduction, convection due to volatile release and radiation due to inter particle
radiation.

An effective thermal conducitivity, $k_{\text {eff, }}$ will be used. The effective conductivity accounts for solid conduction and inter particle radiation and neglects the gas conductance (Kolbeinsen 1994).

$$
k_{e f f}=\left(1-\sqrt{1-\varepsilon_{b}}\right) k_{R}+\frac{\sqrt{1-\varepsilon_{b}}}{\frac{1}{k_{R}}+\frac{1}{k_{p}}}
$$




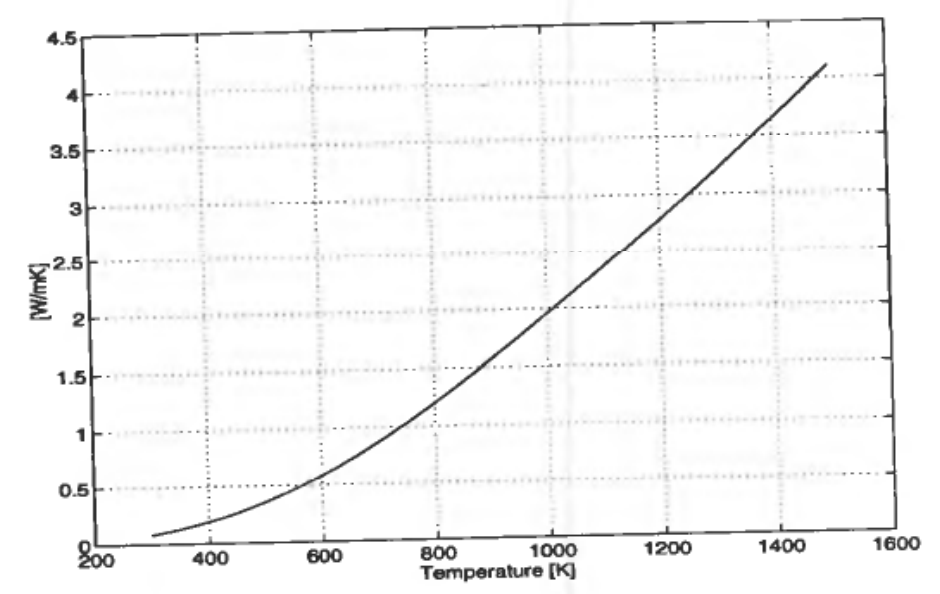

Figure 4. Coke bed effective thermal conductivity.

Where $\varepsilon_{b}$ is the bed voidage and $k_{R}$ is due to radiation given by

$$
k_{R}=\frac{0.04 C_{R}}{\frac{2}{\epsilon}-1} \cdot\left(\frac{T}{100}\right)^{3} \cdot d_{p}
$$

where

$d_{p} \quad$ average particle diameter $[\mathrm{m}]$

$\epsilon$ particle emissivity

$T$ average temperature [K]

$C_{R}$ constant

$k_{p}$ is the thermal conductivity for a particle with porosity

$$
k_{p}=k_{s}\left(1-\varepsilon_{p}\right)
$$

$k_{s}$ is the thermal conductivity for a coke particle without pores.

The effective thermal conductivity is seen to increase with increasing temperature (Fig. 4).

\section{The coke bed}

The coke bed can be considered as a packed bed of porous particles of different shapes and sizes. In formulating the coke bed mass- and energy balance equations, only bulk phenomena are considered.

The coke particles are treated as a bulk mass described by a bulk density, $\rho_{c}$ $\left(\left[\mathrm{kg} / \mathrm{m}^{3}\right]\right)$. The green coke enters the outermost periphery of a horizontal rotating hearth. The hearth rotates with rotational speed denoted $\omega$ ([rps]). After the completion of one revolution, the coke particles are mechanically moved by the rabbles in the radial direction to the next concentric path (Fig. 5).

It is assumed that the rabbles cause an axial coke bed mixing. The mixing will be described by an operator $K$. It is assumed that no back-mix flow of the coke bulk exists. After the completion of each concentric path, all the coke mass is transported into the next concentric path. It is assumed that each path has the same area. The paths widen as approaching the centre of the hearth. 


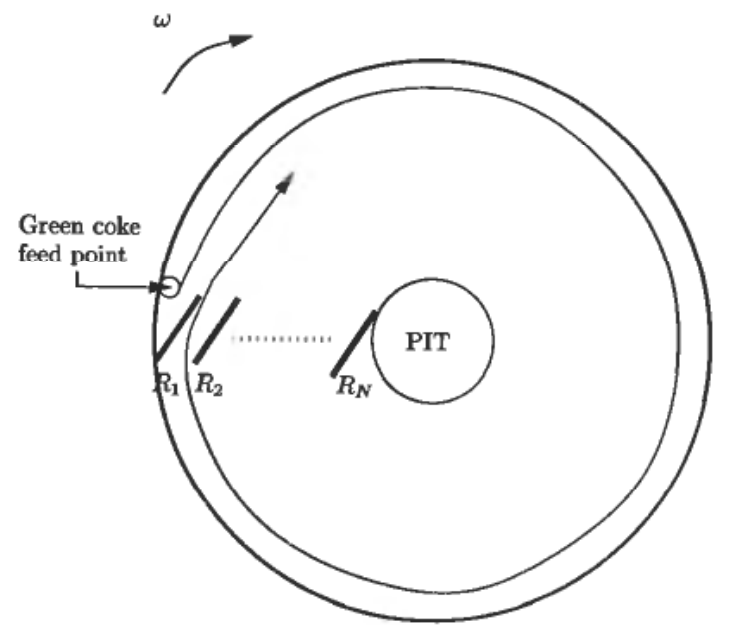

Figure 5. Overview of the rotating coke bed. The coke is transplanted in concentric paths with angular velocity, $\omega . R_{1}, 2, \ldots, R_{N}$ denote the rabbles.

\subsection{The mass balance}

Let $N$ denote the total number of paths, which equals the number of rabbles. The coke particles are transported from the outer most path denoted $j=1$ to the innermost path, denoted $j=N$.

Let $R_{j}$ and $R_{j+1}$ denote the outermost and innermost radii of path $j$, respectively. The rabbles are assumed located so that each path has the same area

$$
\forall i, j: \quad \int_{R_{i}}^{R_{i+1}} 2 \pi r d r=\int_{R_{j}}^{R_{j+1}} 2 \pi r d r
$$

Define

$$
m_{c}(\theta, j, z)=\int_{R_{j}}^{R_{j+1}} \rho_{c} \cdot r d r
$$

$m_{c}($ ) denotes mass of coke per unit radian per unit height. By assuming the density being independent of $r, R_{j} \leq r \leq R_{j+1}, m_{c}$ can be written

$$
m_{c}(\theta, j, z)=\rho_{c} \cdot \Delta R_{j} \cdot\left(R_{j}+R_{j+1}\right)
$$

The mass balance can now be written

$$
\frac{\partial m_{c}}{\partial t}+v_{\theta} \frac{\partial}{\partial \theta} m_{c}+w_{c}=0
$$

with boundary conditions

$$
\begin{aligned}
& j=1, \theta=0: m_{c} v_{\theta}=w_{f} \\
& j>1, \theta=0: m_{c}=\int_{0}^{z_{c}} K(z, \xi) m_{c}(2 \pi, j-1, \xi) d \xi
\end{aligned}
$$

where

$$
\begin{aligned}
w_{c} & \text { mass loss }[\mathrm{kg} / \mathrm{m} \mathrm{rads}] \\
w_{f} & \text { green coke feed rate }[\mathrm{kg} / \mathrm{s} \mathrm{m}] \\
K & \text { mixing operator }
\end{aligned}
$$


$Z_{c}$ coke bed height

$v_{\theta}$ coke angular velocity; [ $\left.\mathrm{rad} / \mathrm{s}\right]$

$v_{\theta}=2 \pi \omega$

$w_{c}$ is due to water and volatile releases

$$
w_{c}=\sum_{i} w_{c, i}
$$

where

$$
\begin{aligned}
w_{c, i}=\int_{R_{j}}^{R_{j+1}} g_{i} r d r & =-m_{i, 0} \cdot \frac{d \eta_{i}}{d t} \\
& =m_{i, 0} \cdot k_{i, 0} e^{E_{i} / R T_{c}} \cdot\left(\eta_{i}\right)^{n i} \\
& =m_{i, 0} \cdot k_{i, 0} e^{E_{i} / R T_{c}} \cdot\left(\frac{m_{i}}{m_{i, 0}}\right)^{n_{i}}
\end{aligned}
$$

where $m_{i}$ is the density of component $i$ and $m_{i, 0}$ denotes the initial density.

The operator $K$ describes the axial mixing caused by the rabbles. $K$ is determined by the degree of mixing and must fulfill the following condition

$$
\int_{0}^{z_{c}} K(\xi, z) d \xi=1
$$

Coke combustion and dust generation are assumed to occur at the surface of the coke bed. This is modeled as a reduction in the coke bed height

$$
\begin{gathered}
m_{c}\left(Z_{c}\right)\left(\frac{\partial Z_{c}}{\partial t}+v_{\theta} \frac{\partial Z_{c}}{\partial \theta}\right)=w_{c, c} \\
w_{c, c}=\int_{R_{j}}^{R_{j+1}}\left(g_{d}+g_{c}\right) r d r
\end{gathered}
$$

The coke components mass balances will also be formulated. Let $i$ denote coke component, $i \in\left[\mathrm{H}_{2} \mathrm{O}, \mathrm{H}_{2}, \mathrm{CH}_{4}, \mathrm{C}_{18} \mathrm{H}_{12}\right]$. For each of the coke components, the mass balances will be formulated.

$$
\frac{\partial m_{i}}{\partial t}+v_{\theta} \frac{\partial m_{i}}{\partial \theta}+w_{c, i}+\frac{m_{i}}{m_{c}} \cdot w_{c, c}=0
$$

The boundary conditions are

$$
\begin{aligned}
& j>1, \theta=0: m_{i}(\theta, j, z)=\int_{0}^{z_{c}} K(z, \xi) m_{i} d \xi \\
& j=1, \theta=0: v_{\theta} \cdot m_{i}=w_{f, i}
\end{aligned}
$$

\subsection{The energy balance}

With the plug-flow assumption the energy balance becomes

$$
m_{c} c_{c} \frac{\partial T_{c}}{\partial t}+v_{\theta} m_{c} c_{c} \frac{\partial T_{c}}{\partial \theta}=\Delta R_{j} \frac{\partial}{\partial z}\left(k_{e f f} \frac{\partial T_{c}}{\partial z}\right)+\sum_{i} \Delta H_{i} w_{c, i}
$$

With boundary conditions

$$
j=1, \theta=0: T_{c}=T_{\text {green }}
$$




$$
\begin{aligned}
j \neq 1, \theta & =0: T_{c}=\frac{1}{m_{c}} \int_{0}^{Z_{c}} K(z, \xi) T_{c}(2 \pi, j-1, \xi) m_{c}(2 \pi, j-1, \xi) d \xi \\
z & =0: \quad-k_{e f f} \frac{\partial T_{c}}{\partial z}=k_{l} \frac{\partial T_{l}}{\partial z} \\
z & =Z_{c}: k_{e f f} \frac{\partial T_{c}}{\partial z}=\Phi_{g c}+\Phi_{c l}
\end{aligned}
$$

where

$c_{c}$ average coke heat capacity $[\mathrm{J} / \mathrm{kgK}]$

$T_{c}$ coke temperature [K]

$k_{e f f}$ effective coke bed conductivity [W/mK]

$\Delta H_{i}$ reaction enthalpy [J/kg]

$T_{\text {green }}$ green coke temperature [K]

$T_{l} \quad$ lining temperature $[\mathrm{K}]$

$\Phi_{c l}$ heat flux from the coke bed to the lining $\left[\mathrm{W} / \mathrm{m}^{2}\right]$

$\Phi_{g c}$ heat flux from the gas to the coke bed [W/m²]

$\Phi_{c r}$ heat flux from the coke bed to the rabbles $\left[\mathrm{W} / \mathrm{m}^{2}\right]$

The coke heat capacity is dependent on the temperature. The following relationship can be used (Perry and Green 1984)

$$
c_{c}=2 \cdot 673+0.002617 \cdot T_{c}-116900 \cdot T_{c}^{-2}
$$

The heat fluxes can be written

$$
\begin{aligned}
& \Phi_{g c}=F_{g c} \frac{\epsilon_{c}+1}{2} \cdot \sigma \cdot\left(\epsilon_{g} T_{c}^{4}\right)+h_{g c} \cdot\left(T_{g}-T_{c}\right) \\
& \Phi_{c l}=F_{g l} \epsilon_{l} \epsilon_{c}\left(1-\epsilon_{g}\right) \sigma\left(T_{c}^{4}-T_{l}^{4}\right)
\end{aligned}
$$

In addition, heat flux between the coke and the rabbles $\left(\Phi_{c r}\right)$ is considered. $\Phi_{c r}$ is expressed as a function of $\theta$ in the following way;

$$
\Phi_{c r}(j, \theta, z)= \begin{cases}h_{c r} \cdot\left(T_{c}-T_{r}\right) ; & \theta=2 \pi \\ 0 & \text { otherwise }\end{cases}
$$

where $h_{c r}$ is an effective heat transfer coefficient and $T_{r}$ is the rabble temperature.

\section{The gas phase}

The gas phase can be considered as a combustion chamber and serves as a heat exhanger. It is the energy supplied to the coke bed which is of main importance, not the detailed gas flow pattern.

The gas components considered are

- air: $\mathrm{O}_{2}, \mathrm{~N}_{2}$

- volatiles: $\mathrm{H}_{2}, \mathrm{CH}_{4}, \mathrm{C}_{18} \mathrm{H}_{12}$

- water from the coke bed

- fuel gas

- combustion products: $\mathrm{H}_{2} \mathrm{O}$ and $\mathrm{CO}_{2}$

A steady state gas model will be used. The dynamics of the gas are much faster than that of the coke bed. The excititations in the gas states are assumed slow compared to the dynamic modi of the gas. 


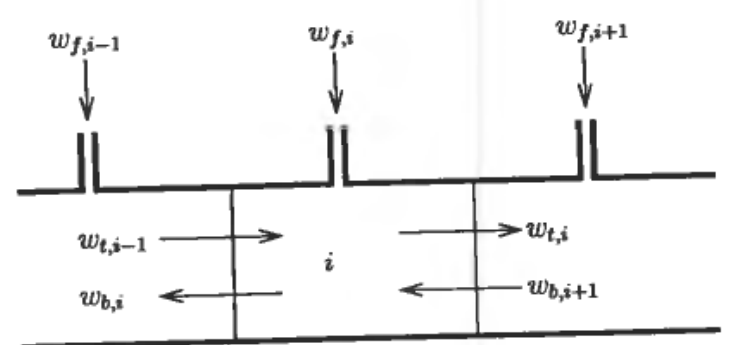

Figure 6. Staged reactor with internal back-mix flow.

\subsection{The gas flow model}

The gas flow pattern is complicated. The overall bulk gas flow is directed towards the centre of the hearth and further through the stack. Air wickets are distributed on the ceiling and in the side walls. Burners are located on the ceiling. Water vapour and by hydrocarbons enters the gas phase from the coke bed. False air from the outside will also influence the gas phase.

Only gas flow in the radial direction is considered. Mixing in the axial and the angular direction is assumed due to the turbulent character of the gas flow.

Radial flow with radial mixing will be modeled as a series of mixed vessels with an internal back-mix flow (Fig. 6). The vessels have different volumes. Also the vessels have one or several feed streams corresponding to the supply of process air and fuel gas and to the mass transfer from the coke bed. A plug flow model with a dispersion term could alternatively be used. By increasing the number of vessels, the two models can be used to represent the same flow pattern. This is discussed in Froment and Bischoff (1990).

The following notation is used: $w_{f, i}$ denotes the feed stream entering the vessel. For simplicity only a single feed stream is shown. $w_{f, i}$ represents the sum of the process air, fuel gas and mass flow from the coke bed. $w_{t i}$ denotes the total forward mass flow rate. $w_{b, i}$ denotes the back flow rate. $w_{i}$ denotes the net mass flow from vessel $i$ to vessel $i+1$. Then

$$
w_{t, i}=w_{i}+w_{b, i+1}
$$

It is assumed that the back-mix flow can be modeled (Singstad 1992)

$$
w_{b, i}=b_{i} \cdot w_{i}
$$

where $b_{i}$ is the back-mix coefficient for stage $i$. If $N$ represents the number of stages, the boundary conditions are written

$$
\begin{aligned}
w_{0} & =0 \\
b_{I}=b_{N+1} & =0
\end{aligned}
$$

\subsection{The mass balances}

The total mass balance equation for vessel $i$ can be written

$$
\frac{\partial \rho_{i}}{\partial t}+\frac{1}{V_{i}}\left(-w_{i-1}+w_{i}-w_{f, i}\right)=0
$$


where

$\rho_{i} \quad$ gas density vessel $i\left[\mathrm{~kg} / \mathrm{m}^{3}\right]$

$V_{i}$ volume of vessel $i\left[\mathrm{~m}^{3}\right]$

$w$ mass flow $[\mathrm{kg} / \mathrm{s}]$

For each of the gas components $j$ in vessel $i$ the following mass balance can be written

where

$$
\begin{aligned}
\frac{\partial\left(\rho_{i} y_{j, i}\right)}{\partial t}= & \frac{1}{V_{i}}\left(w_{t, i-1} y_{j, i-1}-w_{b, i} y_{j, i}-w_{t, i} y_{j, i}\right. \\
& \left.+w_{b, i+1} y_{j, i+1}+w_{f, i} y_{j, f}\right)+\left(S^{\mathrm{T}} \cdot g_{i}\right)_{j}
\end{aligned}
$$

$y_{y, i} \quad$ mass fraction of component $j$ in vessel $i[\mathrm{~kg} / \mathrm{kg}]$

$y_{j . f}$ mass fraction of component $j$ in feed stream $[\mathrm{kg} / \mathrm{kg}]$

$g_{i}$ vector of mass rates of combustion $\left[\mathrm{kg} / \mathrm{m}^{3} \mathrm{~s}\right]$

$S$ stoichiometric matrix

This can be written using vector notation

$$
\rho_{i} V_{i} \frac{\partial y_{i}}{\partial t}=w_{t, i-1}\left(y_{i-1}-y_{i}\right)+w_{b, i+1}\left(y_{i+1}-y_{i}\right)+w_{f, i}\left(y_{f}-y_{i}\right)+S^{\mathrm{T}} g_{i} \cdot V_{i}
$$

The stationary total mass balance can be written

$$
\begin{aligned}
\frac{\partial \rho_{i}}{\partial t}=0 \Rightarrow w_{i} & =w_{i-1}+w_{f, i} \\
w_{i} & =\sum_{j=1}^{i} w_{f, j}
\end{aligned}
$$

The stationary component mass balance can then be written

$$
\frac{\partial y_{i}}{\partial t}=0 \Rightarrow w_{t, i-1}\left(y_{i-1}-y_{i}\right)+w_{b, i+1}\left(y_{i+1}-y_{i}\right)+w_{f, i}\left(y_{f}-y_{i}\right)+S^{\mathrm{T}} g_{i} V_{i}
$$

\subsection{The energy balance}

The energy balance can be written for each vessel $i$ (Froment and Bischoff 1990).

where

$$
\frac{\partial}{\partial t}\left(\rho_{i} u_{i}\right)=\sum_{j} w_{i n, j} H_{j}-\sum_{j} w_{o u t, j} H_{j}+Q_{i}+W_{s, i}
$$

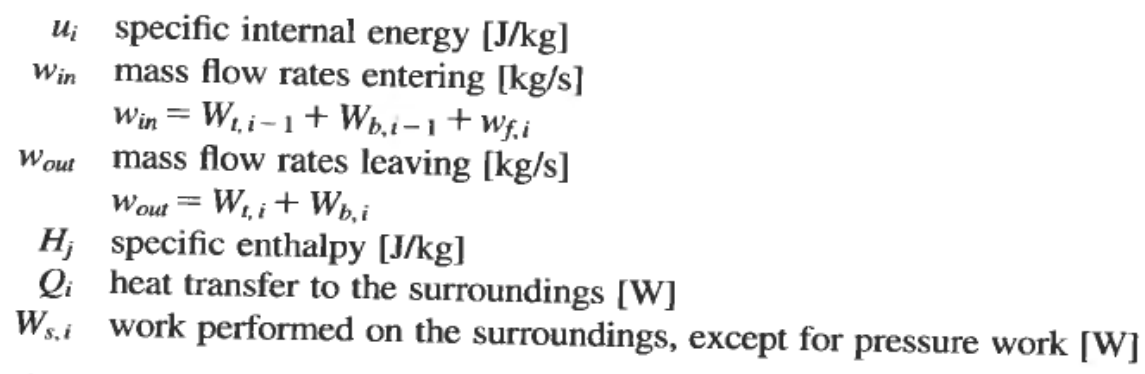

The internal energy can be written

$$
u_{i}=H_{i}-P_{i} / \rho_{i}
$$


where $P_{i}$ denotes total pressure. The enthalpy change in the case of no phase change can be written

$$
d H=c_{p} d T
$$

where $c_{p}$ is the specific heat capacity and $T$ is the temperature.

Neglecting variations in total pressure, considering the case of no phase change and neglecting the work term, the energy balance can be written

$$
\begin{aligned}
V_{i} \rho_{i} \sum_{j} c_{p j} y_{j, i} \frac{\partial T_{i}}{\partial t}= & w_{t, i-1}\left(T_{i-1}-T_{i}\right) \sum_{j} y_{j, i-1} c_{p_{j}}+w_{b, i+1}\left(T_{i+1}-T_{i}\right) \sum_{j} y_{j, i} c_{p_{j}} \\
& +w_{f, i}\left(T_{f}-T_{i-1}\right) \sum_{j} y_{j, f} c_{p_{j}}+Q_{i}+\sum_{k} \Delta H_{k} g_{i, k} V_{i}
\end{aligned}
$$

where

$c_{p_{j}}$ specific heat capacity of component $j[\mathrm{~J} / \mathrm{kgK}]$

$\Delta H_{k}$ reaction enthalpy due to combustion reaction $k[\mathrm{~J} / \mathrm{kg}]$

The stationary energy balance can be written

$$
\begin{gathered}
w_{t, i-1}\left(T_{i-1}-T_{i}\right) \sum_{j} y_{j, i-1} c_{p_{j}}+w_{b, i+1}\left(T_{i+1}-T_{i}\right) \sum_{j} y_{j, i} c_{p_{j}} \\
+w_{f, i}\left(T_{f}-T_{i-1}\right) \sum_{j} y_{j, f} c_{p_{j}}+Q_{i}+\sum_{k} \Delta H_{k} g_{i, k} V_{i}=0
\end{gathered}
$$

Suppose that the gas phase can be described by an average heat capacity

$$
c_{g}=\sum_{j} y_{j} c_{p, j}
$$

The stationary energy balance can then be written

$$
\begin{aligned}
\left\{w_{t, i-1} c_{g}\left(T_{i}-T_{i-1}\right)\right. & \left.+w_{b, i+1} c_{g}\left(T_{i+1}-T_{i-1}\right)+w_{f, i} c_{g}\left(T_{f, i}-T_{i-1}\right)\right\} \\
& +\sum_{k} \Delta H_{k} g_{i, k} \cdot V_{i}+Q_{i}=0
\end{aligned}
$$

$Q_{i}$ is the radiative and convective heat transfer between the gas and the surroundings as described in the previous sections

$$
Q_{i}=Q_{i, g c}+Q_{i, g l}+Q_{i, g r}+Q_{i, g s}
$$

where

$Q_{i, g c}$ heat transfer gas to coke [W]

$Q_{i, g l}$ heat transfer gas to lining [W]

$Q_{i, g r}$ heat transfer gas to rabble [W]

$Q_{i, g s}$ heat transfer gas to soaking pit [W]

\section{The lining}

The lining can be considered as two parallel plates. One plate represents the roof and the wall above the coke bed. The other plate represents the floor.

The lining material consists of different brick materials with an outside steel shell. The lining is subject to inside heating and outside cooling. The following approximations are made 
- The lining is geometrically approximated by an infinite plate.

This is a good approximation due to the small thickness of the lining.

- The temperature gradient of the steel shell is neglected.

The outside steel shell has large thermal conductivity relative to the brick material. In addition the steel shell is much thinner than the brick and has lower heat capacity. Therefore the steel shell is neglected in the model. It will however determine the radiation to the ambient air.

- The thermal properties of the brick material is constant.

This point means neglecting the temperature dependencies of the heat capacity and the thermal conductivity. Different brick material is used, but not
implemented.

Using the given approximations, the lining temperature will be written

$$
\frac{\partial T_{l}}{\partial t}=\alpha_{l} \frac{\partial^{2} T_{l}}{\partial z^{2}}
$$

The boundary conditions are

$$
\begin{aligned}
& z=0:-k_{l} \frac{\partial T_{l}}{\partial z}=\Phi_{\text {in }} \\
& z=D: k_{l} \frac{\partial T_{l}}{\partial z}=\Phi_{o u t}
\end{aligned}
$$

where

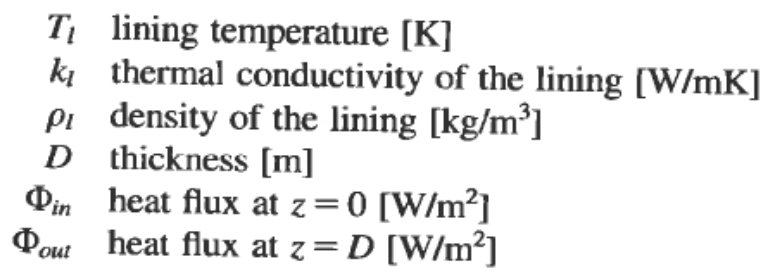

For the wall and the roof, $\Phi_{\text {in }}$ is given by the radiative and convective heat transfer between the wall and the gas and between the wall and the coke bed.

For the roof and the walls, $\Phi_{\text {in }}$ will be written

$$
\Phi_{i n}=h_{g l} \cdot\left(T_{g}-T_{l}\right)+\frac{\epsilon_{l}+1}{2} \cdot \sigma \cdot \epsilon_{g}\left(T_{g}^{4}-T_{l}^{4}\right)
$$

For the hearth floor, $\Phi_{i n}$ is given by the heat transfer between the floor and the coke bed. The floor is in thermal contact with the coke bed. This can be viewed as thermal conduction through composite solid. The total effect is that the coke loses energy to the surroundings and due to the heating of the floor. For the floor, $\Phi_{i n}$ will be written

$$
\Phi_{i n}=k_{e f f} \frac{\partial T_{c}}{\partial z}
$$

where $k_{e f f}$ is the effective coke conductivity. An expression for $\Phi_{\text {out }}$ is written

where

$$
\Phi_{o u t}=\sigma \varepsilon_{o} \varepsilon_{l} F_{o a}\left(T_{a}^{4}-T_{w o}^{4}\right)+h_{o a}\left(T_{a}-T_{w o}\right)
$$

$\epsilon_{o}$ emissivity of outside shell 
$F_{o a}$ form factor

$T_{\text {wo }}$ outside wall temperature [K]

$T_{a}$ ambient air temperature [K]

$h_{o a}$ convective heat transfer coefficient of outer shell surface $\left[\mathrm{W} / \mathrm{m}^{2} \mathrm{~K}\right]$

With $F_{o a}=1$ the heat flux can be written

$$
\Phi_{\text {out }}=\sigma \varepsilon_{o} \varepsilon_{l}\left(T_{a}^{4}-T_{w o}^{4}\right)+h_{o a}\left(T_{a}-T_{w o}\right)
$$

\section{Simulation results}

The simulation model is a numerical means of solving the dynamic partially differential equations describing the coke and the lining mass and temperature profiles. Numerical methods for solving partially differential equations are discussed in Patankar (1980). This simulation model uses the finite difference method. Finite difference methods are easy to implement, and they work well under proper conditions (Sælid 1976).

Based on nominal process data, the stationary temperature profile will be presented. Suppose that the hearth is located in the origin of a coordinate system. The stationary temperature profile in the $r-\theta$ plane in the middle of the coke bed is shown in Fig. 7.

Stationary temperature profiles for the coke bed and the gas phase are shown in Fig. 8. The coke bed temperature profiles are shown as a function of coke bed axial coordinate from the outermost path (lowest path number) to the innermost path (highest path number). The coke surface temperature increases very fast and the surface has nearly the same temperature as the gas. This is mainly due to the intense radial heating. The plot also demonstrates the mixing action caused by the rabbles. In this simulation, perfect mixing is assumed.

A step change is the hearth rotational speed is simulated (Fig. 9). The plot shows the temperature response in the middle of the coke bed as a function of time and path number. The step was introduced at time zero. By increasing the rotational speed, the holding time on the hearth is decreased. From the figure it is seen that the coke bed temperature decreases. The reduction in temperature is most significant at the outermost paths (lowest path numbers).

\section{Conclusions}

A dynamic model of a rotary hearth calciner is proposed.

The model focuses on the thermodynamics of the coke bed including mass and heat transfer between the coke bed and the surroundings. The coke bed is described by a bulk density, mass fractions and temperature. Heat conduction in the coke bed in included. The simulation studies demonstrate that a temperature gradient in the bed is present. However, due to the mixing action caused by the rabbles, the temperature gradients are reduced.

In modeling the gas phase, a stationary model was assumed.

In addition to the thermodynamic model presented in this paper, a more rigorous coke model has been developed describing structural changes in the coke during calcination. The structural changes influence the final coke quality. Coke quality was revealed by properties such as mechanical strength, chemical reactivity and electrical resistivity can be expressed by transformation from the state space. In this framework a model based controller has been developed. 


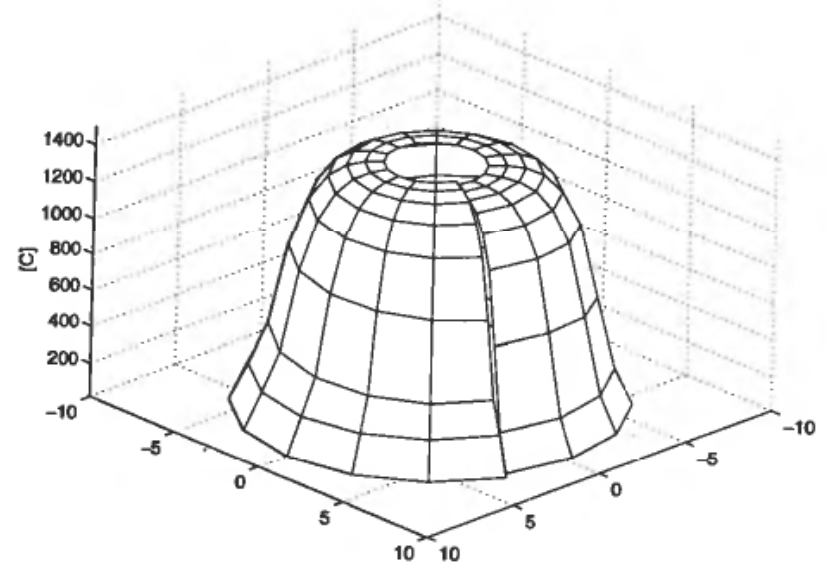

Figure 7. Stationary coke bed temperature profile in the middle $r-\theta$ plane.

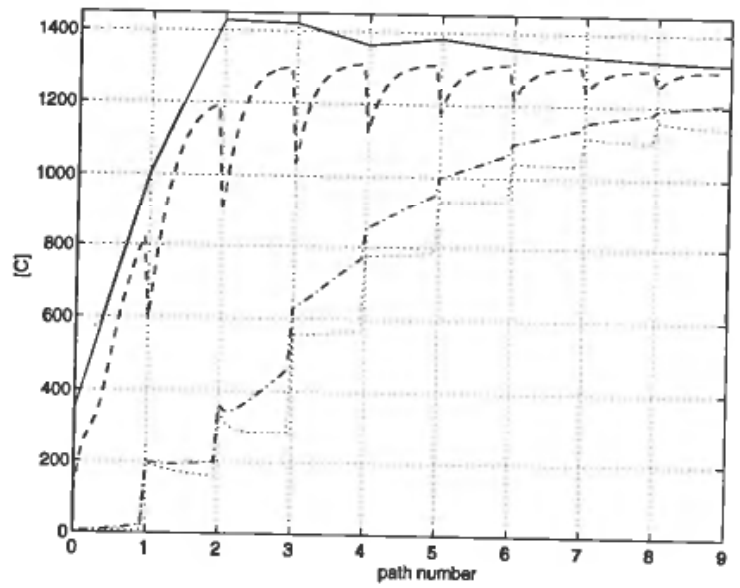

Figure 8. Steady state gas temperature (solid line) and coke bed temperature: Surface temperature (- - , middle temperature $(----)$, bottom temperature $(-\cdot-\cdot-)$.

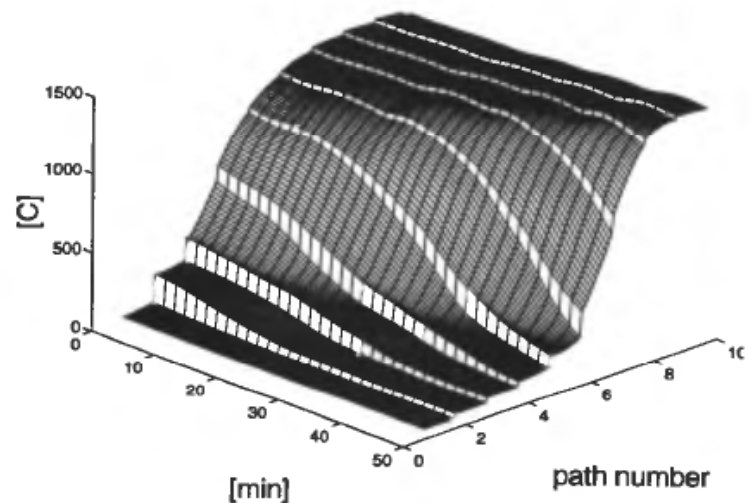

Figure 9. Coke bed temperature response of a step change in the rotational speed. 


\section{ACKNOWLEDGEMENT}

This investigation is supported by the Norwegian Research Council (NFR) on contract STP 27495.

Special acknowledgement is due to Statoil Mongstad Refinery and to Dr. Ramon Fernandez and his staff at the Petroleum Coke Section at the Statoil Product Application and Technical Service Centre.

\section{REFERENCES}

BrandT, H. (1986), Petroleum coke calcining technology, in J. Bacha, J. Newman and J. White (eds), Petroleum Derived Carbons, number 303 in ACS Symposium Series (American Chemical Society, Washington DC).

ChareTTE, A., KocAEFE, D., and CASTONGUAY, L. (1992). Study of green coke calcination, Light Metals, 619-622.

Courson, J. and Richardson, J. (1988), Chemical Engineering, Vol. 1 (Pergamon Press, New York).

DernedDe, E., Charetre, A., Bourgeors, T., and CAstonguay, L. (1986), Kinetic phenomena of the volatiles in ring furnaces, Light Metals, 105, 589-592.

FromeNT, G., and BISCHOFF, K. (1990), Chemical Reactor Analysis and Design (John Wiley \& Sons).

GLCHRIST, J. (1977), Fuels, Furnaces and Refractories, Vol. 21 of International Series on Materials Science and Technology (Pergamon Press, New York).

HotTEL, H., and SAROFIM, A. (1967) Radiative Transfer (McGraw-Hill Book Company).

JONES, S. (1986), Anode carbon usage in the aluminium industry, in J. Bacha, J. Newman and J. White (eds), Petroleum Derived Carbons, number 303 in ACS Symposium Series (American Chemical Society, Washington DC).

KANURY, A. (1977), Introduction to Combustion Phenomena, Vol. 2 of Combustion Science and Technology Book Series (Gordon and Breach Science Publishers).

Kolbeinsen, L. (1994), Personal communication.

KreITH, F., and BLACK, W. (1980). Basic Heat Transfer (Harper \& Row, New York).

LI, K., and FrIDAY, J. (1974), Simulation of coke calciners, Carbon, 12, 225-231.

MARSH, H., (ed.) (1989), Introduction to Carbon Science (Butterworths, London).

MODAK, A. (1978), Radiation from products of combustion, Fire research, 1, 339-361.

PatanKar, S. (1980), Numerical Heat Transfer and Fluid Flow (Hemisphere Publishing Company, New York).

Perron, J., Bui, R., and NGUYEN, T. (1992), Modelisation d'un dour de calcination du coke de petrole: I. le modele, The Canadian Journal of Chemical Engineering, 70, 1108-1119.

Perron, J., POtocniK, V., and Bui, R. (1988), Modelling of the coke calcining kiln, Proc. Int. Symp. Reduction and Casting of Aluminium.

Perry, R., and GreEN, D. (1984), Perry's Chemical Engineers' Handbook (McGraw-Hill Book Company, New York).

RHEDEY, P. (1967), Structural changes in petroleum coke during calcination, Transactions of Metallurgical Society of AIME, 239, 1084-1091.

S FLID, S. (1976), Modelling, estimation and control of a rotary cement kiln, Dr. Ing. Thesis, The Norwegian Institute of Technology, Division of Engineering Cybernetics.

SINGSTAD, P. (1992), Modeling and multivariable control of high pressure autoclave reactors for polymerization of ethene, Dr. Ing. Thesis, The Norwegian Institute of Technology, Division of Engineering Cybernetics.

STORAKER, D. (1989), Måling og beregning av utslepp til luft frå oljeraffineri, Master's thesis, The Norwegian Institute of Technology, Department of Mechanical Engineering, Thermal Energy Division. In Norwegian. 